\title{
Complications associated to percutaneous catheter in preterm and term born children
}

\author{
Martha Alicia Higareda-Almaraz', Paz Alejandra Gutiérrez-Monraz², Ruth Alejandrina Castillo-Sánchez², \\ Juan Carlos Barrera-de León ${ }^{3}$, Ana Bertha Zavalza-Gómez ${ }^{2}$ and Enrique Higareda-Almaraz ${ }^{1}$ \\ ${ }^{1}$ Medical Benefit Services Head Office, Instituto Mexicano del Seguro Social, Colima, Col.; ' $U M A E$, Obstetrics-Gynecology Hospital; ${ }^{3} U M A E$, \\ Pediatrics Hospital, Centro Médico Nacional de Occidente, Instituto del Mexicano Seguro Social, Guadalajara, Jal., Mexico
}

\begin{abstract}
Objective: Identify percutaneous catheter-related complications in preterm and term newborns. Methods: Comparative cross-section. Were included newborns whit percutaneous catheter insertion, blood culture results and distal catheter segment. Were formed two groups: Preterm and term. Results: Were analyzed the data of preterm $(n=50)$ and term $(n=50)$ newborn, the gestational age was $30 \pm 3$ and $40 \pm 2(p=0.01)$. The frecuency in preterm and term newborn was respectively, sepsis catheter 36 and 18\% ( $p=0.02$; OR: 2.56; 95\% Cl: 1.02-7.17), infected catheter 50 and 22\% ( $p=0.01 ;$ OR: 5.92; 95\% Cl: 1.66-23.12), colonized catheter of 24 and 14\% ( $p=0.01$; OR: 3.58; 95\% Cl: 1.32-9.90), local infection 14 and $8 \%(p=0.03$; OR: 1.87; 95\% Cl: 1.45-8.29), infiltration 18 and 4\% ( $p=0.02$; OR: 5.27; 95\% Cl: 1.17-59), accidental removal 6 and $22 \%$ ( $p=0.02$; OR: 0.23; 95\% Cl: 0.05-0.87) and catheter rupture 10 and 28\% ( $p=0.02 ;$ OR: 0.29; 95\% Cl: 0.08-0.98). Conclusions: We found a higher association of infections and infiltrations by percutaneous catheter in preterm and term prevailed in accidental removal and catheter rupture.
\end{abstract}

KEY WORDS: Percutaneous. Catheter. Newborn.

\section{Introduction}

Having a safe venous access is important in hospitalized newborns; this is accomplished by inserting a percutaneous catheter, which is advanced through a peripheral vein and placed in the superior vena cava ${ }^{1}$.

Percutaneous catheters were initially used by Shaw in low-weight children. This technique was used for parenteral nutrition and was shown to be safe and to avoid pain and multiple punctures and immobilizations $^{2}$. Currently, Silastic ${ }^{\circledast}$ percutaneous catheters are the most widely used owing to their easy placement and lower number of complications. However, adverse events have been reported ${ }^{3}$. Some authors have described that prematurity and the use of parenteral nutrition are risk factors for catheter-related sepsis, which has been reported in $23 \%$ of catheters ${ }^{4.5}$.

Some complications are related to catheter initial wrong positioning or shifting inside the vein and, sometimes, the vein is perforated, with fluid extravasation. These factors can cause infiltrations $(5 \%)$, accidental removal $(2 \%)$, pleural effusion (1\%), pericarditis and cardiac tamponade $(1 \%)^{6-8}$.

Low tolerance to infusions with pressure through a percutaneous catheter can cause catheter rupture $(9 \%)^{6,9}$.

The presence of blood thrombi, fibrin or minerals precipitated in the catheter produces catheter occlusion, which is reported in $19 \% \%^{6,10}$.

Currently, the gestational age at which percutaneous catheter insertion-related adverse events are 
more common is not known. Therefore, the purpose of this research was to identify the complications associated with percutaneous catheter in preterm and full-term newborns.

\section{Methods}

The study was carried out from January to December 2015 at the Mexican Institute of Social Security Obstetrics-Gynecology Hospital High Specialty Medical Unit neonatology department in Guadalajara, Mexico.

Medical records from hospitalized newborns of either gender or weight who required percutaneous catheter insertion for parenteral nutrition, with blood culture and percutaneous catheter distal end culture results, were included. Newborns with incomplete medical records and loss of blood and percutaneous catheter culture results were excluded.

The two-proportion formula was used to determine the sample size. The expected percentage of complications in preterm newborns is $65 \%$, whereas in fullterm infants it is $40 \%$. It was calculated with $80 \%$ power, with an estimated sample size of 49 being obtained.

One-hundred medical records of newborns with 2-Fr Vygon percutaneous catheter insertion were reviewed. Data were collected by an investigator, and the obtained information was recorded in a previously-created structured questionnaire.

Gestational age was assessed with the new Ballard scale ${ }^{11}$; birth-weight and gender, number of days the percutaneous catheter remained inserted and blood and percutaneous catheter distal end culture results were collected. Clinical (axillary temperature in centigrade degrees, heart rate in beats per minute, blood pressure in $\mathrm{mmHg}$, coloration changes, capillary refill in seconds, increased ventilatory support and apneas) and laboratory data (leukocyte, platelet and neutrophil counts) were also recorded.

\section{Definition of investigated complications}

- Colonized catheter: isolation of microorganisms at the percutaneous catheter distal end by quantitative culture with $<100,000$ colony-forming units (CFU).

- Infected catheter: isolation of microorganisms at the percutaneous catheter distal end by quantitative culture with $\geq 100,000 \mathrm{CFU}$.
- Local infection: presence of 2 or more signs and symptoms at the point of percutaneous catheter insertion (pain, erythema, inflammation, purulent exudate or palpable venous cord).

- Percutaneous catheter-related sepsis: isolation of microorganisms at the percutaneous catheter distal end with $\geq 100,000$ colony CFU by quantitative culture and positive blood culture for the same microorganism, accompanied by the presence of symptoms according to consensus criteria for sepsis in neonates ${ }^{12}$. Clinical data: temperature curve instability (axillary temperature $<36.5$ or $>37.5^{\circ} \mathrm{C}$ ), tachycardia (heart rate $>180$ beats per minute), hypoperfusion, increased ventilatory support, apneas. Laboratory data: leukocytes $>20,000$ cells $/ \mathrm{mm}^{3}$ or leukopenia $<5,000$ cells $/ \mathrm{mm}^{3}$, thrombocytopenia $<100,000$ cells $/ \mathrm{mm}^{3}$, neutropenia < 1,500, band/neutrophil ratio $>0.2$, and C-reactive protein elevation $>5 \mathrm{mg} / \mathrm{L}$.

- Probable catheter-related sepsis: presence of clinical data consistent with sepsis with blood and percutaneous catheter distal end negative cultures. Clinical signs and symptoms disappear within 48 hours after catheter removal.

- Catheter rupture at insertion zone: presence of fluid leakage at fixation site.

- Accidental removal: shifting of the placement site with percutaneous catheter detachment.

- Infiltration: infused substance accumulation in vein adjacent tissues owing to the catheter shifting from the vein intima to subcutaneous tissue.

- Pleural effusion: pathological fluid accumulation in the pleural space.

- Pericardial effusion: abnormal fluid accumulation in the pericardial cavity, which elevates intra-pleural pressure and this way it exerts a negative effect on the heart function, causing a cardiac tamponade.

- Occlusion: inability to infuse fluid, confirmed by one nurse and one physician.

- Death.

\section{Culture techniques}

- Blood culture: the samples for blood culture were obtained according to standard technique $(1 \mathrm{~mL}$ peripheral blood inoculated into a pediatric tube with PF pediatric Bact/Alert ${ }^{\circledR}$ culture medium). Subsequently, the samples were monitored and analyzed in a Bact/Alert 120 automated system 
for 7 days. Blood culture positive samples were examined under microscope and sub-cultured in chocolate agar for anaerobic microorganisms and in Sabouraud agar, according to the standard method. Assessments to determine these cultures growth were carried out 3,7 and 14 days after seeding. To establish fungal and bacterial sepsis definitive diagnosis, isolation of these pathogens in the cultures was required. This growth was reported as positive or negative according to the MicroScan ${ }^{\circledast} 96$ manufacturer recommendations. The time until the result was obtained was considered within a range from 2 days to 2 weeks. The longest duration was for considering negative cultures for fungi and bacteria.

- Percutaneous catheter quantitative culture: $1 \mathrm{~mL}$ distilled sterile water was passed through the percutaneous catheter lumen and vortexed for 1 minute. Then, $0.1 \mathrm{~mL}$ of this suspension was seeded in an agar plate and incubated for 7 days. The presence of microorganisms indicated a positive culture.

The chi-square test was used to compare between-group difference of proportions, Student's t-test was used for mean differences. Odds ratios (OR) with their $95 \%$ confidence intervals $(\mathrm{Cl})$ were used to identify percutaneous catheter-related complications association with gestational age. Logistic regression was used for adjusted analysis. Statistical significance was considered at a $p$-value $<0.05$. The SPSS program (Chicago, IL, version 19.0) was used for statistical analysis.

This study followed the scientific research ethical principles contained in the Declaration of Helsinki ${ }^{13}$. The protocol did not require informed consent and was accepted by the research committee (registry number: R-2012-1310-37).

\section{Results}

A total of 1020 newborns' medical records were reviewed. Of these, $920(90 \%)$ reported percutaneous catheter insertion, out of which 820 were excluded. One-hundred newborns were included (50 preterm and 50 full-term infants), in whom percutaneous catheter insertion-related complications were assessed.

Table 1 shows the newborns clinical characteristics (Fig. 1). Statistically significant differences were found between preterm/full-term neonates in weight $(1404 \pm 59 / 2922 \pm 68 ; p=0.01)$, gestational age $(30 \pm 2 / 40 \pm 2 ; p=0.01)$, positive blood culture result
Table 1. Clinical characteristics comparison between preterm and full-term newborns with percutaneous catheter insertion

\begin{tabular}{|c|c|c|c|}
\hline \multirow[t]{2}{*}{ Clinical characteristics } & \multicolumn{2}{|c|}{ Groups } & \multirow{2}{*}{$\begin{array}{l} \\
\\
\\
\vdots \\
-\end{array}$} \\
\hline & $\begin{array}{l}\text { Preterm } \\
\mathrm{n}=50(\%)\end{array}$ & $\begin{array}{l}\text { Full-term } \\
n=50(\%)\end{array}$ & \\
\hline irth weight, mean \pm SD & \multicolumn{2}{|c|}{$1404 \pm 592922 \pm 68$} & 0.01 \\
\hline Gestational age, mean \pm SD & $30 \pm 2$ & $40 \pm 2$ & 0.01 \\
\hline Male gender, n (\%) & $23(46)$ & $22(44)$ & 0.50 \\
\hline Age at catheter insertion, mean $\pm \mathrm{SD}$ & $8 \pm 2$ & $7 \pm 2$ & 0.27 \\
\hline $\begin{array}{l}\text { Days with percutaneous catheter, } \\
\text { mean } \pm S D\end{array}$ & $10 \pm 3$ & $12 \pm 2$ & $\frac{0.35}{5}$ \\
\hline Use of parenteral nutrition, n (\%) & $50(100)$ & $50(100)$ & 1.00 \\
\hline Positive blood culture, n (\%) & 17 (34) & $9(18)$ & 0.05 \\
\hline $\begin{array}{l}\text { Positive percutaneous catheter } \\
\text { culture, } \mathrm{n}(\%)\end{array}$ & $37(74)$ & $18(36)$ & 0.01 \\
\hline
\end{tabular}

Student's $t$-test was used to compare between-group mean differences. The Chi-square test was used to compare between-group proportion differences. SD: standard deviation.

(17 [34\%]/9 [18\%]; $p=0.05)$ and percutaneous catheter distal end culture $(37[74 \%] / 18[36 \%] ; p=0.01)$.

Table 2 shows the percutaneous catheter-related complications in preterm/full-term newborns. Catheter-related sepsis was found in $18(36 \%) / 9(18 \%)$ (OR: 2.56; $\mathrm{p}=0.02$ ), colonized catheter in $12(24 \%) / 7$ (14\%) (OR: 3.58; $p=0.01)$, infected catheter in $25(50 \%) / 11(22 \%)(\mathrm{OR}: 5.92 ; p=0.01)$, local infection in $6(12 \%) / 4(8 \%)(O R: 1.87 ; p=0.03)$, infiltration in $9(18) / 2(4)$ (OR: $5.27 ; p=0.02)$, catheter rupture in $5(10 \%) / 14(28 \%)$ (OR: 0.29; $p=0.02)$, accidental removal in $3(6 \%) / 11(22 \%)$ (OR: $0.23 ; p=0.02)$, infiltration in $9(18 \%) / 2(4 \%)$ (OR: $5.27 ; p=0.02)$. No statistical significance was found in other variables.

When logistic regression was calculated with variables in categorical terms being included, gestational age complications in preterm newborns were found to remain statistically significantly associated with the catheter-associated sepsis $(p=0.03)$, infected catheter $(p=0.04)$, infiltration $(p=0.02)$ and probable catheter-associated sepsis variables $(p=0.01$ ) (Table 3$)$.

Bacteria and fungi were found in the blood and percutaneous catheter distal end culture results. Staphylococcus epidermidis was more commonly found in the preterm group (11 [24\%]) than in the full-term group blood cultures $(4[8 \%] ; p=0.01)$. A higher percentage of $S$. epidermidis was found in preterm/full term infants percutaneous catheter culture results, with $18(36 \%) / 8(16 \%)$, respectively $(p=0.01)$, as well 
Gaceta Médica de México. 2018;154

Table 2. Percutaneous catheter-associated complications in preterm and full-term newborns

\begin{tabular}{|c|c|c|c|c|c|}
\hline \multirow[t]{2}{*}{ Complications } & \multicolumn{2}{|c|}{ Groups } & \multirow[t]{2}{*}{ OR } & \multirow[t]{2}{*}{$95 \% \mathrm{Cl}$} & \multirow{2}{*}{$\begin{array}{l}\mathbf{p} \\
\frac{\infty}{\circ} \\
\end{array}$} \\
\hline & $\begin{array}{c}\text { Preterm } \\
n=50\end{array}$ & $\begin{array}{c}\text { Full-term } \\
n=50\end{array}$ & & & \\
\hline Colonized catheter, n (\%) & $12(24)$ & $7(14)$ & 3.58 & $1.32-9.90$ & 0.01 \\
\hline Infected catheter, n (\%) & $25(50)$ & $11(22)$ & 5.92 & $1.66-23.12$ & 0.01 \\
\hline Local infection, $n(\%)$ & $7(14)$ & $4(8)$ & 1.87 & $1.45-8.29$ & 0.03 \\
\hline Catheter-related sepsis, n (\%) & $18(36)$ & $9(18)$ & 2.56 & $1.02-7.17$ & 0.02 \\
\hline Probable catheter-related sepsis, $n(\%)$ & $8(16)$ & $2(4)$ & 4.57 & $1.00-6.25$ & 0.04 \\
\hline Catheter rupture at insertion, $n(\%)$ & $5(10)$ & $14(28)$ & 0.29 & $0.08-0.98$ & 0.02 \\
\hline Accidental removal, $\mathrm{n}(\%)$ & $3(6)$ & $11(22)$ & 0.23 & $0.05-0.97$ & 0.02 \\
\hline Infiltration, $\mathrm{n}(\%)$ & $9(18)$ & $2(4)$ & 5.27 & $1.17-59.00$ & 0.02 \\
\hline Pericardial effusion, n (\%) & $1(2)$ & $1(2)$ & 1.00 & $0.00-37.84$ & 1.00 \\
\hline Pleural effusion, $n(\%)$ & $1(2)$ & $1(2)$ & 1.00 & $0.00-37.84$ & 1.00 \\
\hline Occlusion, $\mathrm{n}(\%)$ & $7(14)$ & $6(12)$ & 1.19 & $0.33-4.43$ & 0.77 \\
\hline Death, n (\%) & $3(6)$ & $3(6)$ & 1.00 & $0.15-6.63$ & 9.00 \\
\hline
\end{tabular}

The Chi-square test was used to compare between-groups proportion differences.

95\% Cl: $95 \%$ confidence interval; OR: odds ratio.

Table 3. Logistic model. Percutaneous catheter-associated complications in preterm and full-term newborns

\begin{tabular}{lccc}
\hline Catheter complications & $\mathbf{p}$ & OR & $\mathbf{9 5 \%} \mathbf{~ C l}$ \\
\hline Infection & 0.01 & 5.92 & $1.66-23.12$ \\
Catheter-related sepsis & 0.01 & 3.91 & $1.00-29.00$ \\
Probable catheter-related sepsis & 0.01 & 2.36 & $1.00-6.25$ \\
Infiltration & 0.02 & 5.27 & $1.37-59.00$ \\
\hline $95 \% \mathrm{Cl}$ :95\% confidence interval: OR. odds ratio & & &
\end{tabular}

as Staphylococcus aureus, with $8(16 \%) / 2(4 \%)$, respectively ( $p=0.01)$ (Table 4$)$.

The vein where the percutaneous catheter was more frequently inserted was the right axillary vein in 11 newborns, out of which $6(12 \%)$ were preterm and $5(10 \%)$ were full-term $(p=0.074)$ (Table 5).

\section{Discussion}

In the present study, a higher association of percutaneous catheter-related infections and infiltrations was found in preterm newborns. In full-term newborns, there was a higher proportion of ruptures and accidental removal.

These data are important in the clinical context in order for strategies intended to correct these complications to be implemented and reduce sequels, which sometimes can be irreversible.
Percutaneous catheters are routinely used in hospitalized newborns in order to maintain a safe venous access $^{1}$.

Eighty percent of blood infections are associated percutaneous catheter ${ }^{14}$. Some authors have found sepsis in $23 \%$ of cases 5 . Risk factors for the development of percutaneous catheter insertion-related infection include prematurity, repeated catheter manipulations, number of days of catheter permanence and use for parenteral nutrition ${ }^{15}$. These data support the results found in this investigation, where a higher percentage of sepsis was found in preterm than in fullterm newborns. Pathogens can reach the catheter via contaminated infusion fluids or by the hematogenous route with bacteria present on the skin, which are in contact with the catheter insertion site and via connections ${ }^{16,17}$. Some authors have described that staphylococcus is the most commonly found species of bacteria found in percutaneous catheter cultures ${ }^{18,19}$. In this research we found similar results.

Catheter shift is common, since it has no special fixation device and these are patients that are very difficult to maintain immobilized ${ }^{20}$. Therefore, radiological visualization is important in order to determine the catheter position ${ }^{21}$. Some publications have demonstrated percutaneous catheter complications owing to defective positioning ${ }^{22-24}$ or catheter shift ${ }^{23}$. These include catheter accidental removal in $2.3 \%{ }^{6}$. 
Table 4. Culture results comparison in preterm and full-term newborns with percutaneous catheter insertion

\begin{tabular}{|c|c|c|c|}
\hline \multirow[t]{2}{*}{ Culture results } & \multicolumn{2}{|c|}{ Groups } & \multirow[t]{2}{*}{$\mathrm{p}$} \\
\hline & $\begin{array}{c}\text { Preterm } \\
n=50\end{array}$ & $\begin{array}{c}\text { Full-term } \\
n=50\end{array}$ & \\
\hline \multicolumn{4}{|l|}{ Blood culture } \\
\hline Candida albicans, n (\%) & $2(4)$ & $0(0)$ & 0.50 \\
\hline Staphylococcus epidermidis, n (\%) & $11(22)$ & $4(8)$ & 0.04 \\
\hline Staphylococcus haemolyticus, n (\%) & $2(4)$ & $0(0)$ & 0.50 \\
\hline Enterobacter cloacae, n (\%) & $1(2)$ & $0(0)$ & 0.50 \\
\hline Serratia marcescens, $\mathrm{n}(\%)$ & $1(2)$ & $0(0)$ & 0.50 \\
\hline Staphylococcus hominis, $\mathrm{n}(\%)$ & $0(0)$ & $1(2)$ & 0.50 \\
\hline Staphylococcus faecium, n (\%) & $0(0)$ & $1(2)$ & 0.50 \\
\hline Pseudomonas aeruginosa, $\mathrm{n}(\%)$ & $0(0)$ & $1(2)$ & 0.50 \\
\hline Klebsiella pneumoniae, n (\%) & $0(0)$ & $2(4)$ & 0.50 \\
\hline Negative, n (5) & $33(66)$ & $41(82)$ & 0.05 \\
\hline \multicolumn{4}{|l|}{ Percutaneous catheter } \\
\hline Staphylococcus epidermidis, n (\%) & $18(36)$ & $9(18)$ & 0.04 \\
\hline Enterobacter cloacae, n (\%) & $2(4)$ & $2(4)$ & 1.00 \\
\hline Pseudomonas aeruginosa, $\mathrm{n}(\%)$ & $0(0)$ & $1(2)$ & 0.50 \\
\hline Staphylococcus aureus, n (\%) & $8(16)$ & $2(4)$ & 0.04 \\
\hline Klebsiella pneumoniae, n (\%) & $1(2)$ & $1(2)$ & 1.00 \\
\hline Staphylococcus haemolyticus, n (\%) & $8(16)$ & $3(6)$ & 0.11 \\
\hline Negative, n (\%) & $13(26)$ & $32(64)$ & 0.01 \\
\hline
\end{tabular}

The Chi-square test was used to compare between-groups proportions difference.

In our investigation, we found a higher proportion in full-term than in preterm newborns, owing to the fact that full-term infants have greater mobility. Catheter advancement until the right atrium can occur, sometimes with secondary perforation and hyperosmolar solutions passage; fluid leakage into the pericardium causes cardiac compression and tamponade ${ }^{25}$, which has been reported in $1 \%$ of cases $^{8}$. In this study, a similar percentage was found in preterm and full-term newborns. Some authors report pleural effusion caused by perfusion fluid extravasation in $1 \%$ of cas$\mathrm{es}^{8}$. In our investigation, this was found in $2 \%$ in both study groups. Percutaneous catheter rupture at the insertion zone is reported in $9 \%$ of cases $^{6}$; and in this study, a higher proportion was found in full-term than in preterm newborns, because a larger amount of solutions is infused and higher pressure is exerted. Percutaneous catheter occlusion is reported in $19 \%$ of cases $^{6}$, and, in this study, a larger proportion
Table 5. Vein used for percutaneous catheter insertion in preterm and full-term newborns

\begin{tabular}{|c|c|c|c|c|}
\hline \multirow[t]{2}{*}{ Percutaneous catheter vein } & \multicolumn{2}{|c|}{ Groups } & \multirow[b]{2}{*}{$\frac{2}{\frac{1}{d}}$} & $p$ \\
\hline & $\begin{array}{c}\text { Preterm } \\
\mathrm{n}=50\end{array}$ & $\begin{array}{c}\text { Full-term } \\
n=50\end{array}$ & & \\
\hline Right axillary, n (\%) & $6(12)$ & $5(10)$ & $\frac{c}{\partial} c$ & 0.74 \\
\hline Left axillary, n (\%) & $5(10)$ & $5(10)$ & $\frac{5}{2}$ & 1.00 \\
\hline Right cubital, n (\%) & $4(8)$ & $0(0)$ & (2) & 0.05 \\
\hline Left cubital, n (\%) & $1(2)$ & $0(0)$ & & 0.50 \\
\hline Right anterior brachial, n (\%) & $1(2)$ & $9(18)$ & $\frac{c}{n}($ & 0.00 \\
\hline Left anterior brachial, n (\%) & $0(0)$ & $1(2)$ & $\frac{0}{5}$ & 0.50 \\
\hline Right accessory cephalic, n (\%) & $3(6)$ & $0(0)$ & $\stackrel{\oplus}{c}$ & 0.12 \\
\hline Left accessory cephalic, n (\%) & $4(8)$ & $1(2)$ & 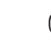 & 0.18 \\
\hline Right brachiocephalic, n (\%) & $0(0)$ & $1(2)$ & $\frac{\overline{0}}{\mathrm{n}}$ & 0.50 \\
\hline Right cephalic, n (\%) & $3(6)$ & $3(6)$ & ( & 0.70 \\
\hline Left cephalic, n (\%) & $2(4)$ & $1(2)$ & 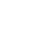 & 0.50 \\
\hline Right median cephalic, n (\%) & $0(0)$ & $2(4)$ & \pm & 0.24 \\
\hline Left median cephalic, n (\%) & $0(0)$ & $2(4)$ & 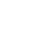 & 0.24 \\
\hline Right median cubital, n (\%) & $0(0)$ & $3(6)$ & 흥 & 0.12 \\
\hline
\end{tabular}

Fischer's exact test was used to compare between-group proportions difference.

was found in preterm newborns; this may be caused by blood thrombi or by the generation of fibrin, owing to the presence of blood in the catheter after an inadequate catheter washing process or retrograde flow. In addition, it can be non-thrombotic as well, caused by precipitated minerals coming from infused solutions or medications ${ }^{9,10}$. Infiltration is reported in $5 \%$ of cases $^{6}$ and, in this study, a higher proportion was found in preterm newborns; this is caused by catheter shift from the vein intima to the subcutaneous tissue.

One limitation of this research is not having carried out complications follow-up in the newborns after catheter removal, which is useful to identify late complications.

The advantages of using percutaneous catheter are that it provides a safe venous access and avoids pain caused by multiple punctures. It is necessary to continue monitoring for the presence of percutaneous catheter-related early and late adverse events. This will help to design new strategies for placing them and correct possible errors, which will allow newborns to have less complications and be early integrated to their immediate family and with no sequels. For the institution, hospitalization days and costs will be reduced. 


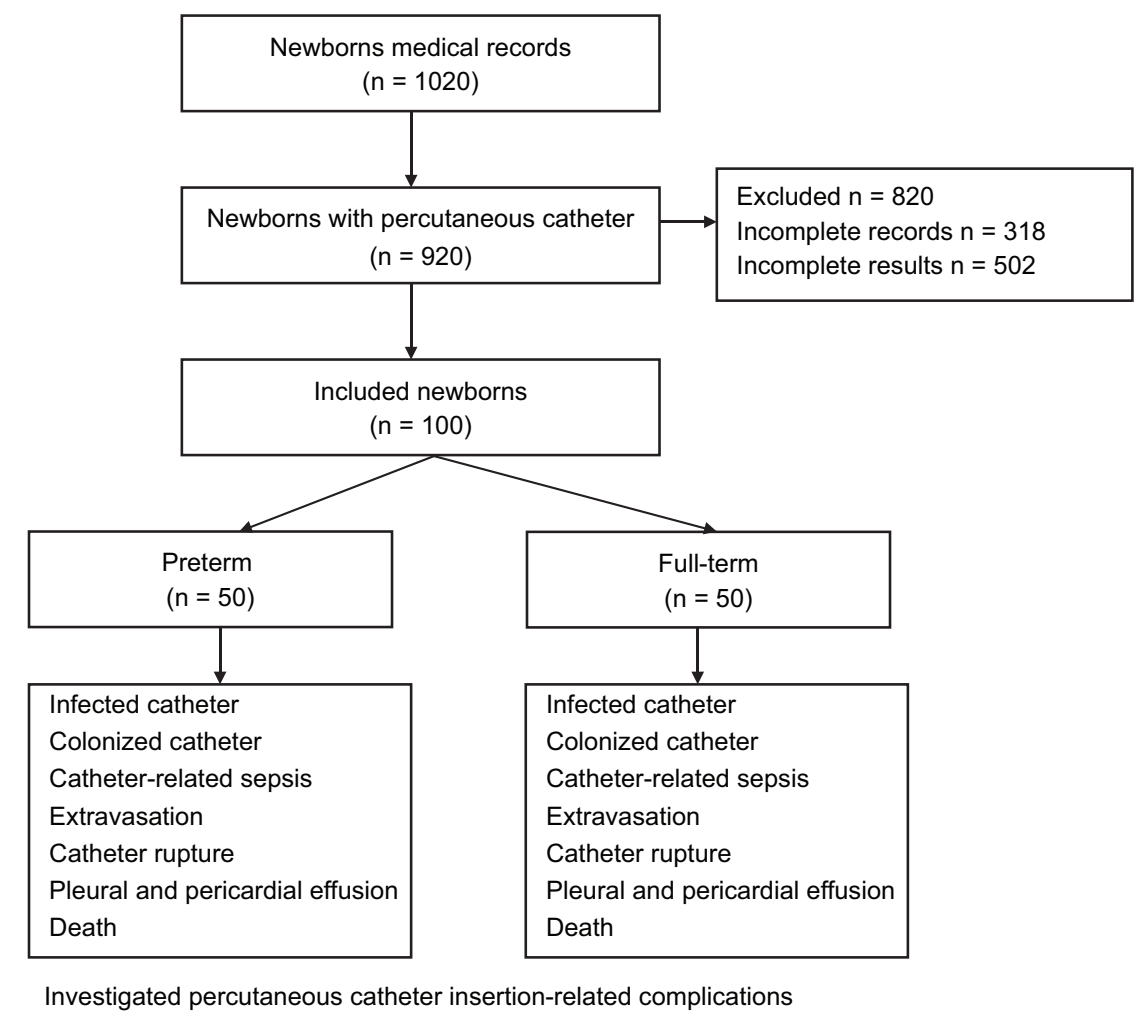

Figure 1. Study profile.

\section{Conclusions}

The results of the present study demonstrate a higher association of percutaneous catheter with infections and infiltrations in preterm newborns. Accidental removal and catheter rupture were found in full-term newborns. Investigating the origin of these complications is necessary in order to establish preventive measures.

\section{Conflicts of interests}

The authors declare not having any conflicts of interests.

\section{References}

1. Menon G. Neonatal long lines. Arch Dis Child Fetal Neonatal. 2003;88:260-2.

2. Shaw JC. Parenteral nutrition in the management of sick low birth weigth infants. Pediatr Clin North Am. 1973;20:333-58.

3. Neubauer AP. Percutaneous central iv in the neonate: experience with 535 silastic catheters. Acta Paediatr. 1995;84:756-60.

4. Mahieu LM, De Muynck AO, leven MM, et al. Risk factors for central vascular catheter-associated bloodstream infections among patients in a neonatal intensive care unit. J Hosp Infect. 2001;48:108-6.

5. López Sastre JL, Fernández Colomer B, Coto Cotallo GD, et al. Prospective evaluation of percutaneous central venous catheters in newborn infants. An Esp Pediatr. 2000;53:138-47.
6. Franceschi AT, da Cunha ML. Adverse events related to the use of central venous catheters in hospitalized newborns. Rev Lat Am Enfermagem. 2010;18:196-202.

7. Darling JC, Newell SJ, Mohamdee O, et al. Central venous catheter tip in the right atrium: a risk factor for neonatal cardiac tamponade. J Perinatol 2001;21:461-4.

8. Leipälä JA, Petäjä J, Fellman V. Perforation complications of percutaneous central venous catheters in very low irthweight infants. J Paediatr Child Health. 2001;37:168-71.

9. Smirk C, Soosay Raj T, Smith AL, et al. Neonatal percutaneous centra venous lines: fit to burst. Arch Dis Child Fetal Neonatal. 2009;94:298-300.

10. Phillips LD. Catéteres de acesso venoso central. En: Phillips LD. Manual de terapia intravenosa. Porto Alegre (RS): Artmed; 2001. p. 334-72.

11. Ballard JL, Khoury JC, Wedig K, et al. New Ballard Score, expanded to include extremely premature infants. J Pediatrics. 1991;119:417-23.

12. Goldstein B, Giroir B, Randolph A. International pediatric sepsis consensus conference: definitions for sepsis and organ dysfunction in pediatrics. Pediatr Crit Care Med. 2005;6:2-8.

13. World Medical Association. World Medical Association Declaration of Helsinki. Ethical principles for medical research involving human subjects. Nurs Ethics. 2002;9:105-9.

14. Eggimann $P, \operatorname{Sax} H$, Pittet $D$. Catheter-related infections. Microbes Infect. 2004:6:1033-42.

15. Yeung CY, Lee HC, Huang FY, et al. Sepsis during total parenteral nutrition: exploration of risk factors and determination of the effectiveness of peripherally inserted central venous catheters. Pediatr Infect Dis J. 1998; $17: 135-42$

16. Hernández R, Águila E. Estudio prospectivo de las complicaciones infecciosas en RN con catéteres de silicona utilizados para infusión de nutrición parenteral. Anal Esp Pediatr. 1996;45:626-30.

17. Sitges-Serra, Linares J. Catheter sepsis: the clue is the hub. Surgery. 1985;97:355-7.

18. Sitges-Serra A, Puig P, Jaurrieta E, et al. Catheter sepsis due to Staphylococcus epidermidis during parenteral nutrition. Surg Gynecol Obstet. 1980;151:481-3.

19. Ponnusamy V, Venkatesh V, Curley A, et al. Segmental percutaneous central venous line cultures for diagnosis of catheter-related sepsis. Arch Dis Child Fetal Neonatal. 2012;97:273-8. 
20. Nadroo AM, Glass RB, Lin J, et al. Changes in upper extremity position cause migration of peripherally inserted central catheters in neonates. Pediatrics. 2002;110:131-6.

21. Coit AK, Kamitsuka MD. Peripherally inserted central catheter using the saphenous vein: importance of two-view radiographs to determine the tip location. J Perinatol. 2005;25:674-6.

22. Colacchio K, Deng Y, Northrup V, et al. Complications associated with central and non-central venous catheters in a neonatal intensive care unit. J Perinatol. 2012;32:941-6.
23. Jain A, Deshpande P, Shah P. Peripherally inserted central catheter tip position and risk of associated complications in neonates. J Perinatol. 2013;33:307-12

24. Srinivasan HB, Tjin-A-Tam A, Galang R, et al. Migration patterns of peripherally inserted central venous catheters at 24 hours postinsertion in neonates. Am J Perinatol. 2013;10:871-4.

25. Chatel-Meijer MP, Roques-Gineste M, Fries F, et al. Cardiac tamponade secondary to umbilical venous catheterization accident in apremature infant Arch Fr Pediatr. 1992;49:373-6. 